\title{
Geographical Moves and Physical Health
}

\author{
Seema Sharma* and Sushma Jaswal \\ Department of Human Development and Sociology, College of Home Science, \\ Punjab Agricultural University, Ludhiana 141 004, Punjab, India \\ *Telephone: 2409476, E-mail: vk_Sharma65@yahoo.co.uk
}

KEYWORDS Migration. Physical Distress. Migrant Labourer. Local Labourer

\begin{abstract}
This study was conducted to assess the magnitude of physical distress among migrant labourers. The study is based upon the sample of 240 labourers (18 years and above in age) drawn in equal numbers from four randomly selected villages and four cycle manufacturing units of Ludhiana district. The results revealed that migrant labourers whose stay was more than one year and the locals experienced more physical distress (fatigue, skin problems, miscellaneous problems) than those migrants whose stay was shorter that is one year or less. The study further indicate that physical distress was found to be significantly more among industrial labour than agriculture labour irrespective of their being local or migrant.
\end{abstract}

\section{INTRODUCTION}

Research on geographical moves has been evident since the turn of the century when large population movements occurred for various reasons. Migration between countries or internal migration was stimulated by changes in agricultural and industrial conditions and generally the populations involved sought to better their predicaments. Any such process involves not only leaving social networks behind but also includes experience at first a sense of loss, dislocation, alienation and isolation (Bhugra 2001). Research carried out on these populations however, indicated that geographical transitions were stressful and likely to increase the risk of changes in mental or physical health. There is some evidence that migration poses a threat to physical health because of dietary changes and exposure to local pathogens against which migrants have no immunity (Beiser 1995).

An additional unknown factor is the strain due to insecurity, fear of the unknown and the possibility of adverse difficulties ahead. Hormones associated with prolong stress have been shown to suppress the immune system because stress hormones mediate the response to environmental and social factor, there is the likelihood of ideal conditions for the development of disease (Amkraut and Solomon 1975).

The study of migrant human populations is intrinsically challenging because of the increase in the world wide migration rates. The social and demographical causes and consequences of migration have been extensively studied, the sequelac of migration to health have been poorly explored.

\section{METHODOLOGY}

The present study was undertaken in Ludhiana district to examine the magnitude of physical distress among migrant labourers in Punjab. The sample for the present study was drawn from cycle manufacturing units and villages of the Ludhiana district. The sample consisting of 240 labourers above 18 years of age was drawn in equal numbers from two enterprises that is cycle manufacturing units $(n=120)$ and agriculture $(n=120)$. Four cycle manufacturing units were selected randomly from a list of cycle manufacturing units employing at least 150 labourers in their enterprise. In case of agricultural enterprise, four villages were selected randomly from two randomly selected blocks of Ludhiana district. The sample for the present study ( $\mathrm{n}=240$ ) included 40 local labourers and 80 migrant labourers in each of the selected enterprises. Further, two groups of migrant labourers were selected purposively on the basis of length of time spent in Punjab after migration. One group of migrant labour included those $(n=40)$ who were here for more than one year while the second group $(\mathrm{n}=$ 40) had spent less than or equal to one year in either of the two enterprises.

The Cornell Medical Index Health Questionnaire developed by Wig et al. (1983) was administered to assess the magnitude of physical distress among labourers.

\section{RESULTSAND DISCUSSION}

Levels of Physical Distress: Table 1 shows that in agricultural sector the level of physical distress among different categories of labourers 
Table 1: Levels of physical distress among agricultural and industrial labourers.

\begin{tabular}{|c|c|c|c|c|c|c|c|c|c|}
\hline & \multirow{2}{*}{$\begin{array}{l}\text { Respondents } \\
\text { Category }\end{array}$} & \multicolumn{8}{|c|}{ Levels of Physical Distress } \\
\hline & & Low $n$ & $(\%)$ & Average $n$ & $(\%)$ & High $n$ & $(\%)$ & Total $n$ & $(\%)$ \\
\hline \multicolumn{10}{|c|}{ A. Agricultural } \\
\hline \multicolumn{2}{|c|}{ 1. Local } & 18 & $(45)$ & 22 & $(55)$ & 0 & $(0)$ & 40 & $(100)$ \\
\hline \multirow{2}{*}{\multicolumn{2}{|c|}{ i) < 1year stay }} & 18 & (45) & 22 & (55) & 0 & $(0)$ & 40 & (100) \\
\hline & & 19 & $(47.50)$ & 21 & $(52.50)$ & 0 & (0) & 40 & (100) \\
\hline Tot & & 55 & $(45.83)$ & 65 & (54.17) & 0 & (0) & 120 & (100) \\
\hline \multicolumn{10}{|c|}{ B. Industrial } \\
\hline \multicolumn{2}{|c|}{ 1. Local } & 14 & (35) & 26 & $(65.00)^{* *}$ & 0 & (0) & 40 & $(100)$ \\
\hline \multicolumn{2}{|c|}{ i) < 1year stay } & 15 & $(37.50)$ & 25 & $(62.50) * *$ & 0 & (0) & 40 & (100) \\
\hline \multicolumn{2}{|c|}{ ii) $>1$ year stay } & 14 & (35) & 24 & $(60.00) * *$ & 2 & (5) & 40 & (100) \\
\hline \multicolumn{2}{|c|}{ Total } & 43 & (33.83) & 75 & $(62.50)$ & 2 & (1.67) & 120 & (100) \\
\hline
\end{tabular}

** Significant at $5 \%$ level

Levels of significance of difference between proportions (z-test)

was of the same level. As many as 45,45 and 47.50 per cent of local, migrants with one year or less stay' and with more than one year of stay' respectively suffered from low level of physical distress whereas remaining proportions of the respective labourers' categories were found to be suffering from average level of physical distress. None among them was found to be suffering with high level of physical distress.

Similarly, in industrial sector, 35 per cent of local labourers, 37.50 per cent of migrant labourers with one year or less stay' and 35 per cent of migrant labourers with more than one year of stay' were suffering from low level of physical distress while the remaining proportion of them were suffering from average level of physical distress. However, 5 per cent migrant labourers with more than one year of stay' suffered from high level of distress. The number of industrial labourers in each category who suffered from average level of physical distress were significantly higher than those who suffered from low level of physical distress.

These observations clearly indicate that physical distress was more in case of industrial labourers as compared to that in agricultural sector. This may be due to the longer and continuous working hours in industrial sector as compared to the agricultural sector. In addition the physical environment could equally be responsible as is also being pointed out by the earlier studies in urban anthropology that migrants cluster together in urban enclaves, characterized by informality of their housing, lack of govt. services and environmental conditions of migrant households are a prime factor in determining their health status (Rahman 1992)

Patterns of Physical Distress: A close examination of mean per cent scores for all the twelve dimensions of physical distress among all agricultural and industrial groups of labourers revealed that the pattern of physical distress is similar among all of them (Table 2). The pattern consisted of four segments, of which each comprised of three dimensions of physical distress arranged/ranked in descending order with respect to the mean per cent scores for each included dimension. The four segments were arranged in a definite sequence as per the descending mean per cent scores of its constituent dimensions of physical distress. The sequence of segments and their constituent dimensions of physical distress were observed to be the same for all groupings of labourers across agricultural and industrial sectors. Accordingly the first segment consisted of fatigability, skin problems and miscellaneous problems. The dimensions of the second segment of physical distress consisted of bad habits, digestive tract problems and problems of the eyes and ears. Problems related to respiratory system, nervous system problems and genitourinary problems formed the third segment of physical distress. The fourth and the last segment comprised of frequency of illness, problems related to cardiovascular system and musculoskeletal system.

Fatigue: It was observed to be the number one dimension of physical distress for all groups of labourers irrespective of their working in agricultural or industrial sector. Comparison of mean 
per cent scores for agricultural and industrial local labourers (Agricultural: 25.71; Industrial: 23.29), migrant labourers with less than one year stay' (Agricultural: 16.14; Industrial: 11.86) and migrant labourers with more than a year stay' (Agricultural: 22.14; Industrial: 20.17) clearly show (Table 2) that it is relatively lesser among the later than the former. It may be due to the fact that agricultural operations, invariably involve a lot of physical labour than industrial operations which are largely mechanized. It could also be noted that fatigue was most pronounced among local labourers followed by migrant labourers with more than one year stay' and was least among migrant labourers with one year or less stay'. It could be due to the fact that most of the migrant labourers with one year or less stay' were younger in age and had spent lesser time on job, than their counterparts in other group.

Skin Problems: The second most prevalent dimension of physical distress among all groups of labourers was problems of skin. The per cent score for this dimension among agricultural and industrial local labourers was 21.43 and 21.14, respectively. The migrant labourers with more than one year stay' had relatively lesser skin problems when compared with their local counterparts for their mean per cent scores was 19.17 for both working in agricultural and industrial sector. The agricultural migrant labourers with one year or less stay had relatively lesser (15.43) skin problems than their counterparts working in the industry (17.14) but also when compared with local labourers and migrant labourers with more than one year stay'. These observations indicate that the extent of skin problems was more pronounced among local labourers.

However, the difference in per cent scores for skin problems between migrant labourers with one year or less stay' working in agricultural and industrial sectors was six times more than that found among their local and migrant labourers with more than one year stay' counterparts. The tentative explanation for these observations could be that the quality of work given to migrant labourers' with one year or less stay' could be inferior than that given to other labourer groups. No statistically significant difference could be observed between all groups of labourers for physical distress caused by skin problems.

Miscellaneous Problems: It was found to be the third most common dimension of physical

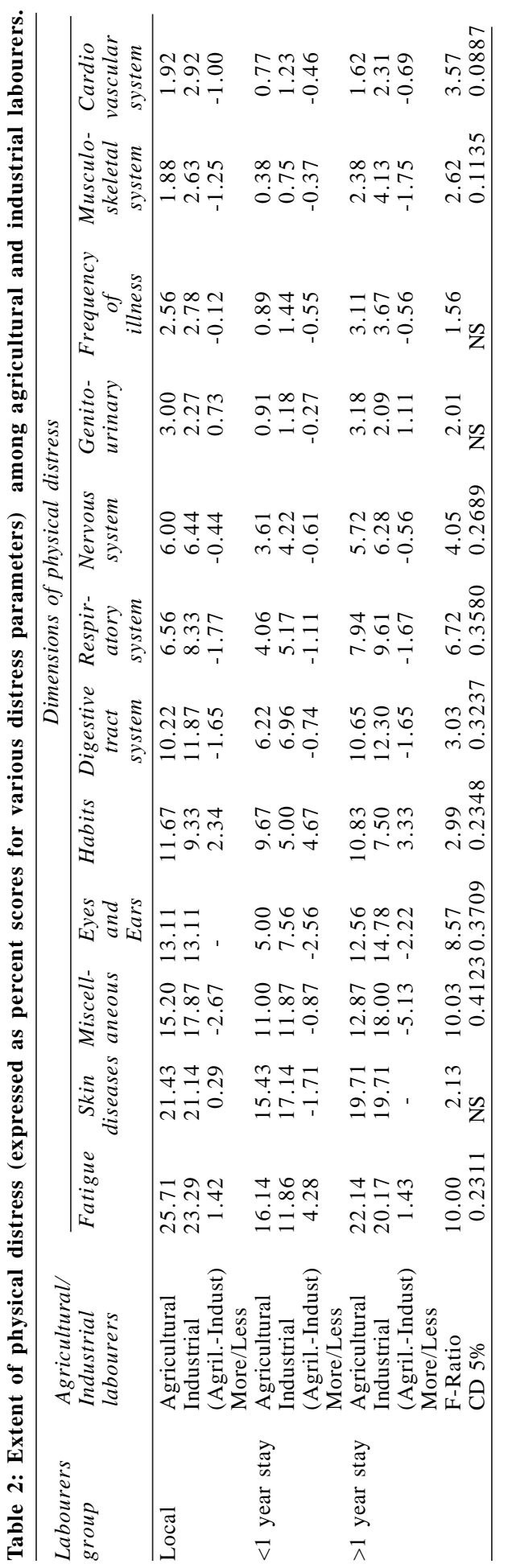


distress among all groups of labourers irrespective of their working in the agricultural or industrial sector. Miscellaneous problems include diseases like anemia, diabetes, stone formation , over weight, under weight etc. Comparison of mean per cent scores for agricultural and industrial local labourers (Agricultural: 15.20 and Industrial: 17.07) migrant labourers with one year or less stay' (Agricultural: 11.00 and Industrial: 11.87) and migrant labourers with more than one year stay' (Agricultural: 12.87 and Industrial: 18.00) clearly show that it is lesser among the former than the later. It is clearly indicated that magnitude of difference was most pronounced for the migrant labourers with more than one year stay' followed by local labourers and least in migrant labourers with one year or less stay'. Statistically all the groups differed significantly from each other (F ratio- 10.03 )

Bad Habits: The fourth most important dimension of physical distress among labourers of all categories was found to be the bad habits like alcohol consumption, smoking, eating tobacco and other narcotics as found by Masi (1989) that migratory stress may result in problems of alcoholism, family disruption and physical illness. The mean per cent scores of physical distress due to bad habits among local agricultural and industrial labourers were 11.67 and 9.33, respectively. The corresponding values of mean scores for agricultural and industrial migrant labourers with one year or less stay' were 9.67 and 5.00 and for migrant labourers with more than one year stay' were 10.83 and 7.50 , respectively. On comparison of these groups, it is evident that local agricultural labourers stood number one for physical distress due to bad habits followed closely agricultural migrant labourers with more than one year stay'. It could also be observed that physical distress due to bad habits is greater in magnitude among labourers working in agricultural setting than those working in the industrial setup.

The magnitude of the difference between mean per cent scores of agricultural and industrial migrant labourers with one year or less stay was two fold that of local labourers. Statistical comparison of these groups showed that difference among the groups are significant ( F-ratio: 2.99 and CD 5\% $=0.2348$ ).

Eyes and Ears Problems: The physical distress caused by problems related to eyes and ears were most prevalent among migrant labour- ers with more than one year stay' working in industrial sector followed by locals. The physical distress due to eyes and ears problems was relatively less among migrant labourers with one year or less stay' being 5.00 for those in agricultural sector and 7.56 for industrial sector. However the magnitude of difference between mean per cent score for agricultural and industrial sector was more (2.56) than that for their migrant counterparts with more than one year stay' (2.22).

Statistical comparison of different categories of labourers showed that they significantly differ from each other with respect to the physical distress scores due to eyes and ears problems (F-ratio: 8.57 and CD 5\% = 0.3709).

Digestive Tract Disorders: The digestive tract problems causing physical distress among industrial labourers were more as compared to those from agricultural sector irrespective of the group of labourers they belonged to. It is evident from table 2 that the mean per cent score for agricultural and industrial local labour 10.22 and 11.87 respectively and the corresponding figures for migrant labourers were 6.22 and 6.96 (with less than one year stay) and 10.65 and 12.30 (with more than one year stay). Statistically all the groups differed significantly from each other (Fratio: 3.03 and $C D 5 \%=0.3237$ ). The migrant labourers had slightly more of digestive tract problems than their local counterparts in agricultural and industry.

Respiratory Problems: Respiratory problems were found to be more among industrial labourers than among agricultural labourers for all groups of labourers. Physical distress due to respiratory problems was found to be more among migrant labourers with more than one year stay' (Agricultural: 7.94 and Industrial: 9.61) than among local labourers (Agricultural: 6.56 and Industrial: 8.33) and migrant labourers with one year or less stay' (Agricultural: 4.06 and Industrial: 5.17). Statistically all the groups were significantly different from each other (F-ratio: 6.72; $\mathrm{CD} 5 \%=0.3580$ ).

Nervous System Problems: Like many other problems causing physical distress among labourers, nervous system problems were relatively less among agricultural labourers (mean per cent score for local: 6.00 and for; migrants (i) with less than one year stay: 3.61 (ii) with more than one year stay: 5.72) than industrial labourers It is also evident that these were more prevalent among local industrial labourers and least 
among migrant labourers (with less than one year stay). Statistically all the groups were significantly different from each other (F-ratio: 4.05 CD 5\%: 0.2689).

Problems Related to Genitourinary System: The mean per cent scores of physical distress due to problems related to genitourinary system were found to be relatively lesser among industrial (2.27) local and migrant labourers (with more than one year stay: 3.18) than their agricultural counterparts (local: 3.00 and migrant labourers with more than one year stay: 3.18 ). On the other hand the migrant labourers who had spent less than one year in the state and had worked in industrial sector showed greater value of mean per cent scores (1.18) than that for their agricultural (0.91) counterparts. However, differences among various groups of labourers were statistically non significant (F-ratio: 2.01). It could be concluded that physical distress due to problems of genitourinary system are more or less of same magnitude in all labourers groups.

Frequency of Illness: No statistically significant difference could be observed between different groups of labourers across agricultural and industrial labourer for physical distress covered through frequency of illness. It being comparable in terms of mean per cent scores for locals (Agricultural: 2.56 and Industrial: 2.78), migrants ('with less than one year stay') Agricultural: 0.89 and Industrial: 1.44) and with more than one year stay' (Agricultural: 3.11 and Industrial: 3.67).

Musculoskeletal System: The magnitude of physical distress due to musculoskeletal system problems were observed to greater among industrial labourers than that observed for the agricultural labourers irrespective of the local and migrant labourers groups. There were statistically significant difference among all groups of labourers (F-ratio: 2.62 CD 5\% 0.1135). The physical distress due to problems related to musculoskeletal system was observed to be the least among migrant labourers with one year or less stay' and magnitude of difference between agricultural and industrial labourers in this case was also least i.e. 0.37 mean per cent score. This difference was almost five times more among local and migrant labourers (with more than one year stay). It indicates that the physical distress due to problems related to musculoskeletal system are pronounced among industrial local and migrant labourers (with more than one year stay).

Cardiovascular System: Perusal of Table 2 shows that physical distress due to problems related to cardiovascular system tend to be greater among industrial (local: 2.92; migrant with less than one year: 1.23 and migrants with more than one year 2.31) than among agricultural labour (local: 1.92, migrant 'with less than one year: 0.77 and migrant with more than one year': 1.62). The statistical comparison of these groups showed that these are significantly different from each other (F-ratio: 3.57; CD5\%: 0.0887).

\section{DISCUSSION}

Therefore, it can be concluded that migrant labourers whose stay was more than one year and the locals experienced more physical distress than those migrants whose stay was shorter that is one year or less. Barros and Ferreira (1976) described a typical clinical condition in Portuguese immigrants which is characterized by fatigue, anxiety, sense of suffocation, dyspnoea, coughing, chills, abdominal and gastric pain, headaches, backache, vomiting, diarrhea, cardiac pains, palpitations, dizziness and collapse. The most frequent cause was 'the strange climate' with reference to the foreign emotional environment. There are four physiological systems which are particularly vulnerable to stress: the cardiovascular system (heart and blood circulation system); the endocrine system (hormone system); the gastrointestinal system (digestive system) and the immune system (body's defence system) (Cox 1993). When individual is under stress, the stomach increases production of hydrochloric acid, which can cause inflammation and eventually lead to sores or ulcers on the lining of the digestive tract. Intense stress levels can increase the risk of developing conditions such as inflammatory bowl disease, stomach pain, diarrhea, constipation, loss of appetite (Joffe 1986). The endocrine system produces chemical messengers or hormones which have an effect on almost every organ in the body. Stress can cause both overproduction and underproduction of several major components of the endocrine system, which in turn affects the major organs including the heart, lungs and brain as well as immune system which is responsible for the body's defense against diseases (Cox 1993). The life styles of migrants such as food preparation, sanitary habits, unpleasant job conditions, relation with people at work, living conditions may be inappropriate maladaptive in new settings (Hertz 1980). In short the health status for residents of more stable communities will be 
less affected by the effects of chronic and acute stresses compared to residents of communities with high rates of residential instability (Boardman 2004)

Further the physical distress was found to be significantly more among industrial labour than agricultural labour. The reason for this may be that rural to urban migrants in the developing world occupy the most economically inferior sector in the city. The housing of urban migrants is characterized by informal dwellings on the out skirts of the urban area, lacking in formal health and sanitation facilities (Mehta 1990). These habitations are generally referred as slums in urban settings as Arya et al. (1984) studied the pattern and prevalence of morbidities and mortalities in an urban slum community of Varanasi district and found morbidity rate $59.6 / 1000$ population in the area of all the morbid spells, $(1.19 \%)$ were because of respiratory infection, $(0.87 \%)$ were due to pulmonary tuberculosis and skin disease (0.84\%) Biswas et al. (1996) also studied the health status of an urban slum community at Calcutta and found respiratory injections and diarrheal disease responsible for $25.1 \%$ and $23.4 \%$ of total illnesses respectively. Economic inferiority of migrants forces them to occupy land more subject to physical and chemical hazards posed by the proximity of heavy industry (Brockerhoff 1995) hence increasing the risk of physical distress with the increase in the length of stay.

Migrants could experience a period of grief after migration, but would gradually recover from it and eventually adjust to the conditions of his new environment. However, he might retain ambivalent feelings towards his homeland. At the same time, it was also assumed that although health care may actually improve as a consequence of migration, existentially present stress factors could either precipitate stress manifestations or cause a shift from one type of illness to another. The move from one environment to another can be considered a crisis situation. The stresses following migration can affect coping patterns and mechanisms which then will become maladaptive. Psychological symptoms and psycho physiological reactions may arise and previ- ously existing ones may be aggravated and possibly lead to disability (Hertz 1994).

\section{REFERENCES}

Amkraut A, Solomon GF 1975. From the symbolic stimulus to the patholphysiologic response immune mechanisms. J Psychi Med, 5: 541-563.

Arya RK, Kumar S, Gaur SD 1984. Pattern and prevalence of morbidities and mortalities and their management in an urban slum community of Varanasi districts. Ind $J$ Preventive \& Soc Med, 15: 9-12.

Barros C, Ferreira, M 1976. Hysteria et Fait Psychosomatigue Chez Immigrant Portugais. Acta Psychiatrica Belgica, 76: 551-578.

Beiser M 1995. Immigrant and refuges children in Canada. Canad J Psychi, 40: 67-72.

Bhugra D 2000. Migration and schizophienia. Acta Psychiatr Scand Suppl, 407: 68-73.

Biswas R, Biswas AB, Chatterjee S, Chowdhury G, Bhandari A 1996. A study of the health status of an urban slum community at Calcutta. Ind J Comm Med, 3: 126-129.

Boardman JD 2004. stress and physical health: the role of neighborhoods as mediating and moderating mechanisms. Social Sci Med, 58: 2473-2483.

Brockerhoff M 1995. Child survival in big cities: The disadvantages of migrants. Soc Sci Med, 40: 137138 .

Cox L 1993. Stress and Health. In: Hard Labour Part 2 Section 1, London: London Hazards Center, Interchange Studies, pp. 13-18.

Hertz DG 1980. Remigration: Psychological problems of the returning resident. In: WM Pferfer, W Schoene (Eds): Psychopathologic in Kulturvergleich. Stuttgart: Ferdinand Enke Verlag, pp. 282-293.

Hertz DG 1994. The stress of migration: Adjustment problems of migrant and displaced families. In: DG Hertz (Ed.): Family Issues. An Interdisciplinary View on Family Stresses and Their Consequences. Jerusalem: Gefen Publishing House, pp. 140-141.

Joffe M 1986. Stress and Health. In: Hard Labour. Part 2 Section 1, London: London Hazards Center, Interchange Studies, pp. 42-45.

Masi R 1989. Multiculturalism, medicine and health Part-IV: Individual Considerations. Canad Fam Phys, 35: 251-254.

Mehta S 1990. Spatial mobility in India: Evolving patterns, emerging issues and implications. Pop Geo, 36: 10-24.

Rehman S 1992. The influence of socio-economic characteristics on subsequent infant and child mortality. J Fam Wel, 38: 20-24 .

Wig NN, Pershad D, Verma SK 1983. C.M.I. Health Questionnaire. Agra: Psychological Corporation. 